\title{
Sodium Dodecyl Sulphate-Polyacrylamide Gel Electrophoresis of Cell-surface Proteins as an Aid to the Identification of the Bacteroides fragilis Group
}

\author{
By IAN R. POXTON AND ROBERT BROWN \\ Bacteriology Department, University of Edinburgh Medical School, \\ Teviot Place, Edinburgh, EH8 9 AG, Scotland
}

(Received 30 November 1978)

\begin{abstract}
The outer-membrane complexes from 40 strains of Bacteroides, representing eight of the species included in the Bacteroides fragilis group, were released by EDTA treatment. The component polypeptides were examined by sodium dodecyl sulphate-polyacrylamide gel electrophoresis on slab gels. Within a species (biotype) the patterns produced indicated marked similarities in the structures of the surface proteins among the strains examined. The patterns produced by strains belonging to different species, however, showed fewer similarities. An unknown organism could therefore be identified to species level using this technique and a few selected biochemical tests.
\end{abstract}

\section{INTRODUCTION}

Bacteroides fragilis, B. vulgatus, B. distasonis, B. thetaiotaomicron, B. eggerthii, B. ovatus, $B$. uniformis and $B$. splanchnicus are species included in the $B$. fragilis group. They are characterized as being obligately anaerobic, non-pigmented, bile-tolerant, glucosefermenting, Gram-negative rod-shaped bacteria. These organisms are frequently isolated from clinical specimens, predominantly from wounds, intra-abdominal infections, the blood and perirectal or pelvic sites (Finegold, 1977; Willis, 1977; Wren et al., 1977). Bacteroides fragilis, a minor component of the faecal flora, is the member of the group most commonly isolated from infections, whereas $B$. vulgatus, $B$. thetaiotaomicron and $B$. uniformis are predominantly faecal isolates.

After an organism has been identified as a member of the family Bacteroidaceae by culture and microscopic examination, and is distinguished from the fusobacteria by gasliquid chromatography of the volatile fatty acid metabolic products, at least eight, sometimes variable, biochemical tests have to be performed for identification to species level (Holdeman et al., 1977).

Recently, polyacrylamide gel electrophoresis (PAGE) of cellular proteins has been employed in attempts to sub-classify the Bacteroides genus. Strom et al. (1976) used discontinuous gradient PAGE and examined proteins solubilized by sonication of whole cells of several species of Bacteroidaceae. Swindlehurst et al. (1977) used the SDS (sodium dodecyl sulphate)-PAGE procedure to examine members of the species $B$. melaninogenicus; these workers used hot SDS extracts of whole cells. It was possible to identify members of the Bacteroidaceae to species, subspecies and strain levels.

The present study evaluates the use of SDS-PAGE in examining the cell-surface proteins released from the bacteria by controlled treatment with EDTA at $45^{\circ} \mathrm{C}$ followed by mild ultrasonic disruption. When this is used in conjunction with a few selected biochemical tests it becomes a relatively rapid, simple aid to identifying the species within the $B$. fragilis group.

0022-1287/79/0000-8343 \$02.00 @ 1979 SGM

Vol. 112, No. 1 was issued 31 May 1979 
Table 1. Strains of Bacteroides examined by SDS-PAGE and results of selected biochemical tests

Species Strain

B. fragilis

NCTC 9344

NCTC 8560

NCTC 10581

NCTC 10584

GNAB 4

GNAB 8

GNAB 49

GNAB 101

GNAB 102

GNAB 104

GNAB 105

B. vulgatus

NCTC 10583

GNAB 25

GNAB 30

GNAB 31

GNAB 34

GNAB 35

GNAB 37

GNAB 38

GNAB 44

GNAB 107

GNAB 120

B. distasonis

ATCC 8503

GNAB 22

GNAB 27

GNAB 39

B. thetaiota-

NCTC 10582

omicron

GNAB 1

GNAB 2

GNAB 7

B. eggerthii

NCTC 11155

GNAB 21

GNAB 24

GNAB 41

B. uniformis

ATCC 8492

VPI 11227

GNAB 18

VPI 11368

B. ovatus

ATCC 8483

B. splanchnicus

NCTC 10825

Source duction

Indole
pro-
duction

\section{NCTC}

NCTC

NCTC

NCTC

Wound swab RIE

Wound swab RIE

Skin RIE

Wound swab WGHE

Wound swab WGHE

Wound swab WGHE

Wound swab WGHE

NCTC

Faeces

Faeces

Faeces

Faeces

Faeces

Faeces

Faeces

Faeces

Wound swab WGHE

Wound swab WGHE

ATCC

Faeces

Faeces

Faeces

NCTC

Wound swab RIE

Wound swab RIE

Wound swab RIE

NCTC

Faeces

Faeces

Faeces

ATCC

VPI

Wound swab RIE VPI

ATCC

NCTC

$\begin{array}{llllll}- & - & - & - & - & \end{array}$

$\begin{array}{llllll}- & - & - & - & - & \mathrm{NT}\end{array}$



$\begin{array}{llllll}- & - & - & - & & \end{array}$

$\begin{array}{llllll}- & - & - & - & - & \mathrm{NT}\end{array}$

$\begin{array}{llllll}- & - & - & - & - & \mathrm{NT}\end{array}$

$\begin{array}{llllllll}- & - & - & - & - & \mathrm{NT}\end{array}$

$\begin{array}{llllll}- & - & - & - & - & \mathrm{NT}\end{array}$

$\begin{array}{llllllll}- & - & - & - & - & \mathrm{NT}\end{array}$

$\begin{array}{llllll}- & - & - & - & \mathrm{NT}\end{array}$

$\begin{array}{llllllll}- & - & - & - & - & \mathrm{NT}\end{array}$

$\begin{array}{lllll}- & + & - & - & \mathrm{NT}\end{array}$

$\begin{array}{lllll}- & + & - & - & \mathrm{NT}\end{array}$

$\begin{array}{llllll}- & + & - & - & \mathrm{NT}\end{array}$

$\begin{array}{lllll}- & + & - & - & \mathrm{NT}\end{array}$

$\begin{array}{lllll}- & + & - & - & \mathrm{NT}\end{array}$

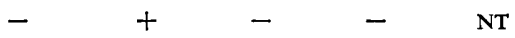

$\begin{array}{llll}- & + & - & \mathrm{NT}\end{array}$

$\begin{array}{lllll}- & + & - & - & \mathrm{NT}\end{array}$

$-\quad+\quad-\quad-\quad$ NT



$\begin{array}{lllll}- & + & - & - & \mathrm{NT}\end{array}$

$-\quad+\quad+\quad-\quad \mathrm{NT}$

$-\quad+\quad+\quad-\quad \mathrm{NT}$

$\begin{array}{llll}- & + & + & \mathrm{NT}\end{array}$

$\begin{array}{llll}- & + & + & \mathrm{NT}\end{array}$

$+\quad+\quad+\quad-\quad$ NT

$+\quad+\quad+\quad-N T$

$+\quad+\quad+\quad-\quad$ NT

$+\quad+\quad+\quad$ NT

$+\quad+\quad-\quad-\quad-$

$\begin{array}{lllll}+ & + & - & - & -\end{array}$

$\begin{array}{lllll}+ & + & - & - & - \\ + & + & - & - & -\end{array}$

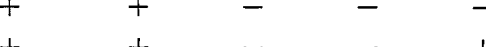

$\begin{array}{lllll}+ & + & - & - & + \\ + & - & + & - & +\end{array}$

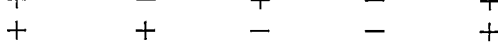

$+\quad+\quad-\quad-\quad+$

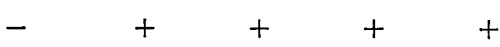

$+\quad-\quad-\quad-\quad-\quad+2$

+ , Positive; - , negative; NT, not tested.

Non-standard abbreviations: VPI, Virginia Polytechnic Institute, Blacksburg, Virginia, U.S.A.; RIE, Royal Infirmary, Edinburgh; WGHE, Western General Hospital, Edinburgh; GNAB, Lab. strain no.

Rha, Rhamnose; Tre, trehalose; ManOH, mannitol; Suc, sucrose.

\section{METHODS}

Growth of bacteria and preparation of protein extracts. Freeze-dried inocula of the strains listed in Table 1 were cultured in $10 \mathrm{ml}$ of Robertson's cooked meat broth (modified by Watt, 1973) and incubated for $48 \mathrm{~h}$ at $37^{\circ} \mathrm{C}$ by the standard anaerobic procedure of Collee et al. (1972). One $\mathrm{ml}$ of this culture was inoculated into $50 \mathrm{ml}$ proteose peptone/yeast extract (PPY) medium (Holbrook et al., 1977). After incubation for $20 \mathrm{~h}$, $3 \mathrm{ml}$ of the culture was removed for purity checks and biochemical testing (Table 1) while the remainder was harvested by centrifugation at $3000 \mathrm{~g}$ for $30 \mathrm{~min}$ and washed three times in phosphate buffered saline $(0 \cdot 15$ $\mathrm{M}-\mathrm{NaCl}$ in $50 \mathrm{mM}-\mathrm{Na}_{2} \mathrm{HPO}_{4} / \mathrm{NaH}_{2} \mathrm{PO}_{4}$ buffer, $\left.\mathrm{pH} 7 \cdot 4\right)$. The bacteria were resuspended in $2 \mathrm{ml}$ phosphate buffered saline containing $10 \mathrm{~mm}$-EDTA and transferred to a glass test tube. To remove the outer membranes 
and associated molecules, the suspension was incubated for $30 \mathrm{~min}$ at $45^{\circ} \mathrm{C}$, then vortex-mixed, treated in an ultrasonic bath (model 6441A; Dawe Instruments, Western Ave, London) for 1 min and again vortexmixed. After two centrifugations $(6000 \mathrm{~g}$ for $30 \mathrm{~min})$ the supernatant fluid contained outer-membrane vesicles together with released proteins and other molecules. The above conditions were standardized to give optimum release of protein without lysis of the bacterial cytoplasmic membrane. EDTA was removed by dialysis for 4 to $5 \mathrm{~h}$ in two successive 1 litre volumes of $0.01 \mathrm{M}$-Tris $/ \mathrm{HCl} \mathrm{pH} 7.4$ containing $0.01 \%(\mathrm{v} / \mathrm{v})$ 2-mercaptoethanol and the samples were concentrated by dusting the dialysis bags with a fine layer of Sephadex G-100 and leaving at $4{ }^{\circ} \mathrm{C}$ for $16 \mathrm{~h}$. The concentrated extracts were freeze-dried and dissolved in SDS-PAGE sample buffer to give a protein concentration of $2 \mathrm{mg} \mathrm{ml}^{-1}$. Sample buffer was 0.0625 $\mathrm{M}$-Tris/ $\mathrm{HCl}$ pH 6.8 containing $2 \%$ (w/v) SDS, $10 \%$ (v/v) glycerol, $1 \%$ (v/v) 2-mercaptoethanol and $0.001 \%(\mathrm{w} / \mathrm{v})$ bromophenol blue. Samples were heated in a boiling water bath for $3 \mathrm{~min}$ just prior to application to the gel.

Polyacrylamide gel electrophoresis. This was adapted from the method of Laemmli (1970). Slab gels $(170 \times 140 \mathrm{~mm})$ of $10 \%(\mathrm{w} / \mathrm{v})$ acrylamide with a $10 \mathrm{~mm} 4 \%(\mathrm{w} / \mathrm{v})$ stacking gel were used to run up to 12 samples in a Raven (Haverhill, Suffolk, CB9 7UU) slab gel apparatus. Buffers were as described by Laemmli (1970). Samples $(100 \mu \mathrm{l})$ of extract containing $200 \mu \mathrm{g}$ protein were electrophoresed at constant voltage, first at $50 \mathrm{~V}$ until the sample had entered the separating gel (approx. $1 \mathrm{~h}$ ) then at $150 \mathrm{~V}$ until the bromophenol blue was near the bottom of the gel (approx. $4 \mathrm{~h}$ ). Staining was carried out overnight and de-staining was done over $4 \mathrm{~h}$ with the solutions described by Poxton \& Sutherland (1976).

Protein estimation. Samples of EDTA extracts were assayed for protein using the method of Lowry et al. (1951).

Characterization of strains used. All test strains had previously been characterized by the procedures of Duerden et al. (1976). Selected biochemical tests, however, were performed on each strain after growth in PPY medium (Table 1). These served as a check on the previous results. They included tests on indole production and the fermentation of rhamnose, trehalose, sucrose and mannitol by the methods described by Duerden et al. (1976).

\section{RESULTS AND DISCUSSION}

The EDTA-extracted proteins from eight different type species included in the $B$. fragilis group were examined on the same gel (Fig. 1). The patterns of bands were quite different; only a few matching lines were shared and there was no possibility of picking out diagnostic bands typical of the $B$. fragilis group as a whole. However, the individual species within the group showed species-specific patterns.

For 11 strains of the species $B$. fragilis (syn. B. fragilis subsp. fragilis) there were many matching bands in all of the extracts (Fig. 2), perhaps with the exception of NCTC 8560 (track 2) which did not share many bands with any of the other strains. The double high molecular weight and triple low molecular weight sequences of bands (arrows) appeared to be common to the other 10 strains. There were close similarities between tracks 1 and 5 and between tracks $3,7,8,9,10$ and 11 .

Ten strains of $B$. vulgatus (syn. B. fragilis subsp. vulgatus) gave similar patterns with many matching bands (Fig. 3). The sequence of five or six high molecular weight bands (arrow) appeared to be characteristic of this species. Many other sequences of bands were shared by these strains and an overall similarity of patterns was observed.

Four strains of $B$. distasonis (syn. B. fragilis subsp. distasonis) were examined with a strain of debated identity (Fig. 4). All four strains of $B$. distasonis gave a strongly staining, high molecular weight band of similar, but not necessarily identical, molecular weight (arrow). The dubious strain (track 2, Fig. 4) had been received as B. vulgatus but the results of subsequent biochemical re-testing (Table 1) and the pattern produced on the gel confirmed that it was $B$. distasonis. It was, in fact, identical with strain ATCC 8503 (track 1, Fig. 4). Strains GNAB 27 and GNAB 39 (tracks 4 and 5, Fig. 4) showed almost identical patterns. These were faecal isolates taken several days apart from the same person.

Three indole-positive species of Bacteroides which were originally regarded as B. thetaiotaomicron (syn $B$. fragilis subsp. thetaiotaomicron) are now grouped into at least three separate species: $B$. thetaiotaomicron, $B$. eggerthii and $B$. uniformis. Their patterns on gels (Fig. 5) showed that they share several common polypeptides but there are closer similarities between strains from the same species. The four strains of $B$. thetaiotaomicron (tracks 1 to 4) 


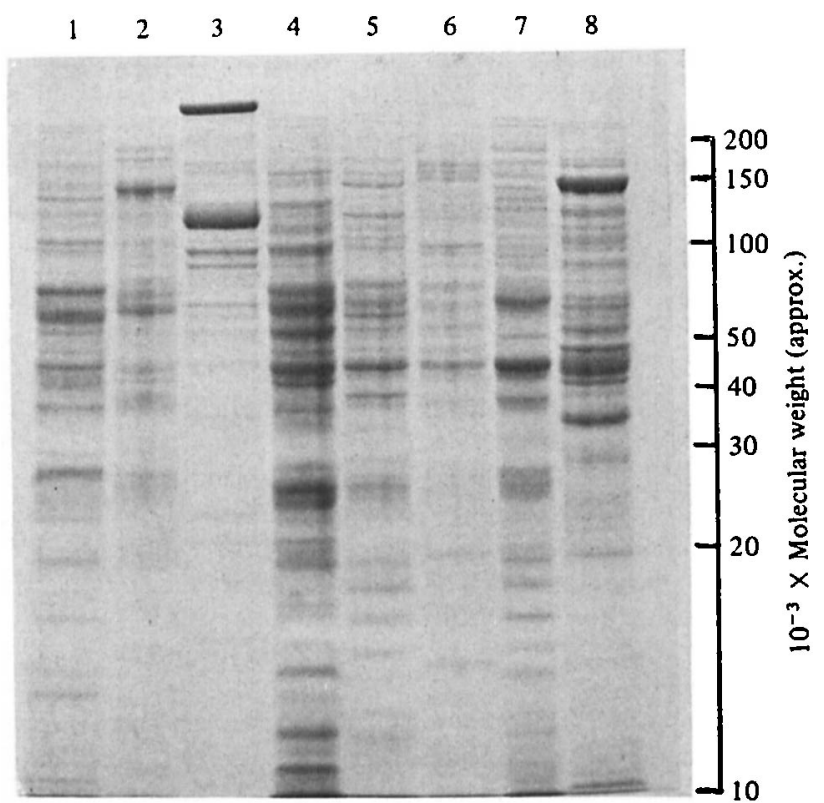

Fig. 1. SDS-PAGE of EDTA-extracted cell-surface proteins of Bacteroides species on $10 \%$ acrylamide slab gels (for details, see Methods). Track $1, B$. fragilis NCTC $10584 ; 2$, B. vulgatus NCTC $10583 ; 3, B$. distasonis ATCC $8503 ; 4, B$. thetaiotaomicron NCTC 10582; 5, B. eggerthii NCTC 11155; 6, B. ovatus ATCC 8483; 7, B. uniformis ATCC 8492; 8, B. splanchnicus NCTC 10825.

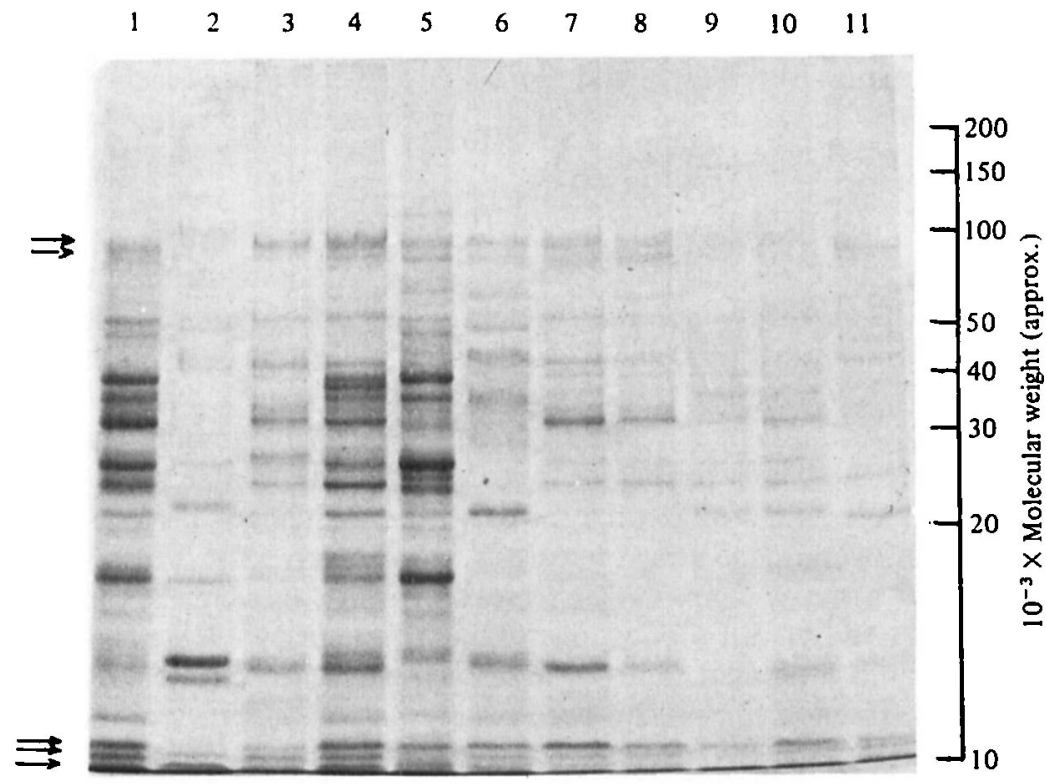

Fig. 2. SDS-PAGE of EDTA-extracted cell-surface proteins of strains of Bacteroides fragilis on $10 \%$ acrylamide slab gels (for details, see Methods). Track 1 , NCTC 9344; 2 , NCTC $8560 ; 3$, NCTC 10581 ; 4, NCTC 10584; 5, GNAB 4; 6, GNAB 8; 7, GNAB 49; 8, GNAB 101; 9, GNAB $102 ; 10$, GNAB 104; 11, GNAB 105. Arrows indicate bands characteristic of the species. 


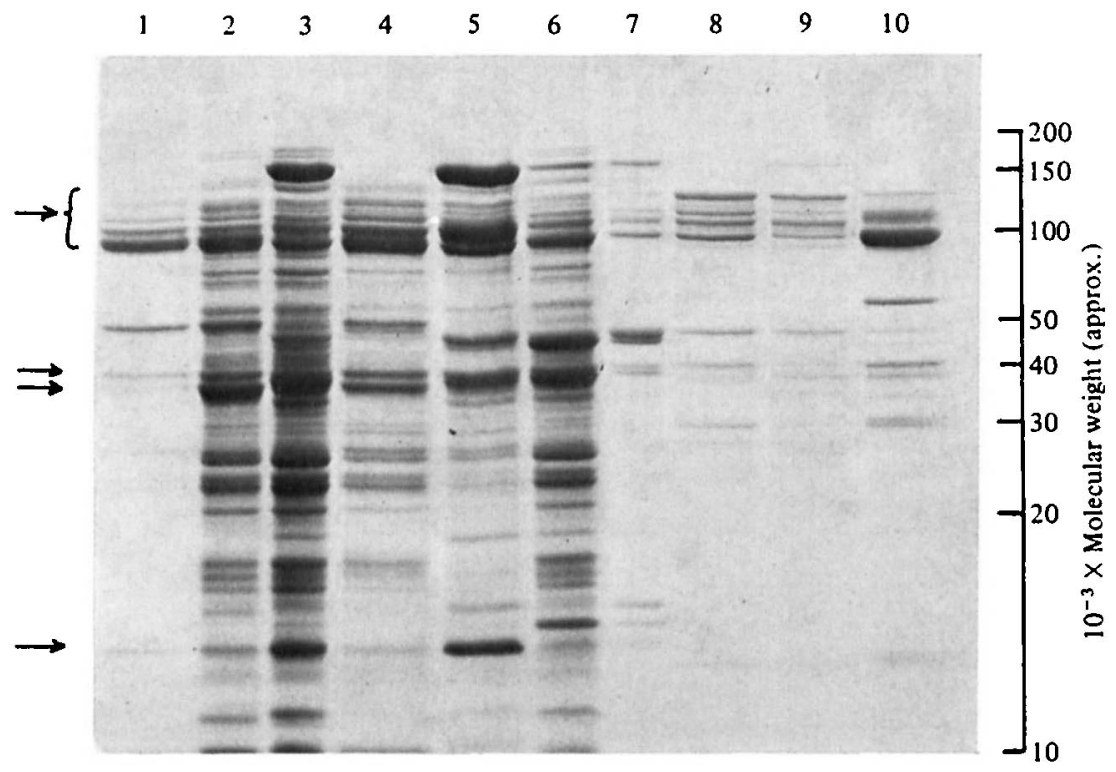

Fig. 3. SDS-PAGE of EDTA-extracted cell-surface proteins of strains of Bacteroides vulgatus on $10 \%$ acrylamide slab gels (for details, see Methods). Track 1, GNAB 25; 2, GNAB 30; 3, GNAB 31 ; 4, GNAB 34; 5, GNAB 35; 6, GNAB 37; 7, GNAB 38; 8, GNAB 44; 9, GNAB 107; 10 , GNAB 120. Arrows indicate bands characteristic of the species.

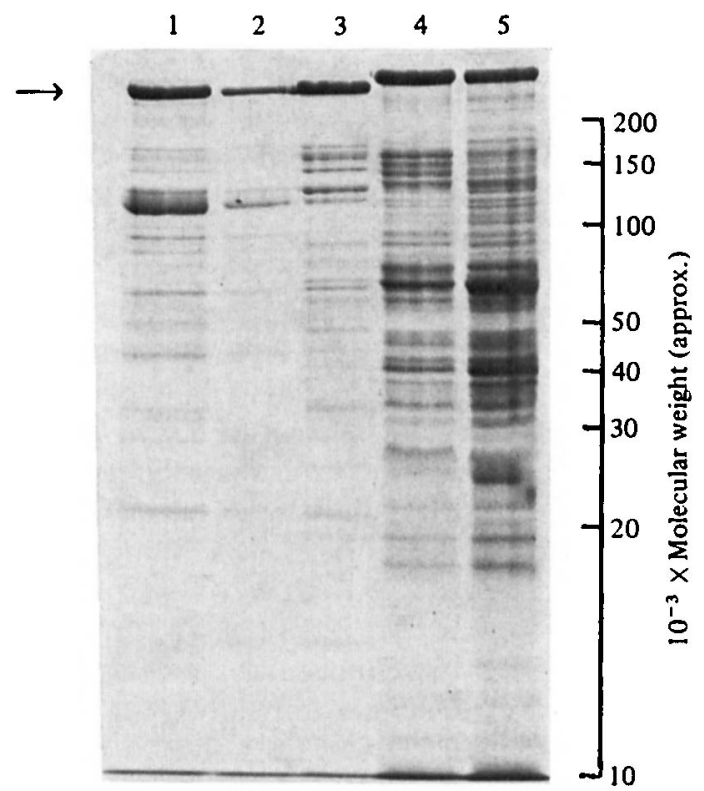

Fig. 4. SDS-PAGE of EDTA-extracted cell-surface proteins of strains of Bacteroides distasonis on $10 \%$ acrylamide slab gels (for details, see Methods). Track 1, ATCC $8503 ; 2$, mis-labelled $B$. vulgatus; 3, GNAB 22; 4, GNAB 27; 5, GNAB 39. Arrow indicates a band characteristic of the species. 


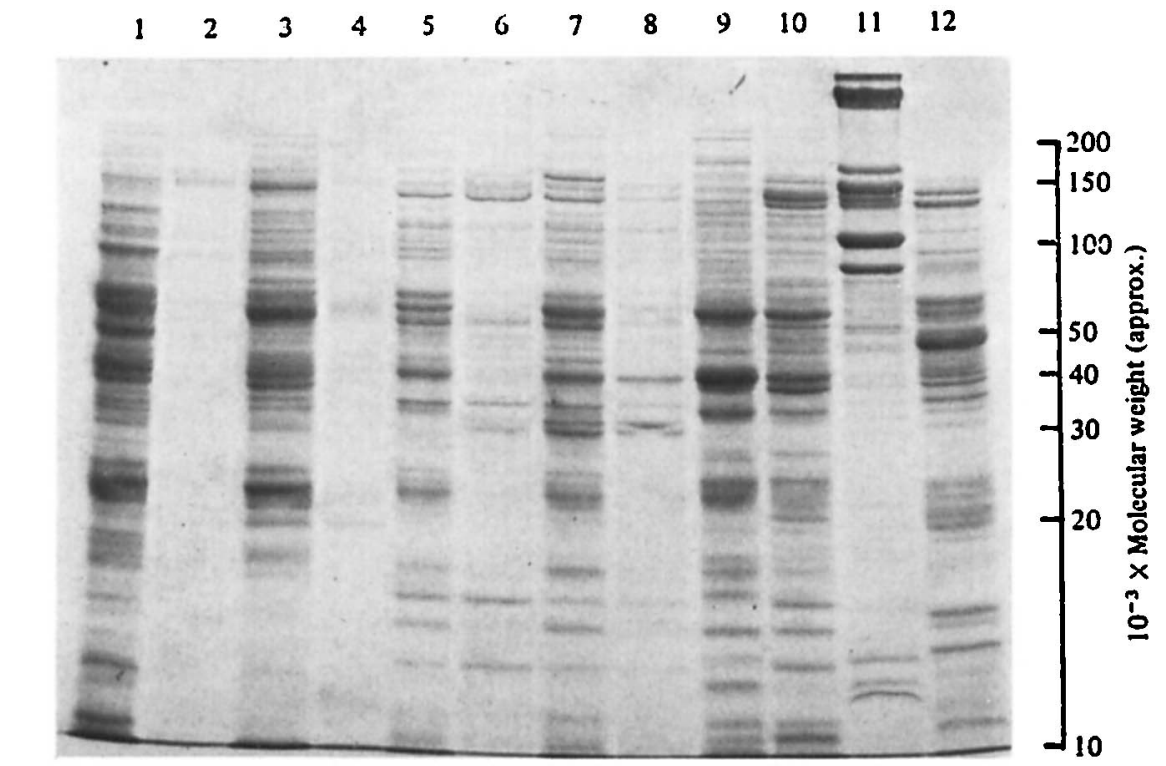

Fig. 5. SDS-PAGE of EDTA-extracted cell-surface proteins of strains of indole-positive Bacteroides species on $10 \%$ acrylamide slab gels (for details, see Methods). Bacteroides thetaiotaomicron: track 1, NCTC 10582; 2, GNAB 1; 3, GNAB 2; 4, GNAB 7. Bacteroides eggerthii: track 5, NCTC 11155 ; 6, GNAB 21; 7, GNAB 24; 8, GNAB 41. Bacteroides uniformis: track 9, ATCC 8492; 10, VPI $11227 ; 11$, GNAB $18 ; 12$, VPI 11368 .

showed many matching bands. Similarly, the four strains of $B$. eggerthii (tracks 5 to 8) closely matched each other. The strains of $B$. uniformis (tracks 9 to 12), however, showed variation: strains ATCC 8492 (track 9) and VPI 11227 (track 10) matched very closely, and strain VPI 11368 (track 12) shared several common polypeptides with these two; however, strain GNAB 18 (track 11) was very different from these although the results from standard biochemical tests showed it to be identical with VPI 11368. Tracks 2 and 4 were unfortunately weakly stained although the amount of protein was the same in all the samples applied to this gel. A duplicate gel, using freshly prepared samples, gave the same result. In the original gel the bands in tracks 2 and 4 could be easily compared with 1 and 3 .

This study presents much evidence that similar biotypes of Bacteroides possess similar polypeptides in their surface layers. The patterns of $B$. fragilis NCTC 8560 and B. uniformis GNAB 18 show, however, that organisms indistinguishable by biochemical tests can differ significantly in their surface chemistry; thus the results of biochemical tests alone can be misleading and should be used with caution. Due to our present lack of knowledge of the cell-surface chemistry and serology of Bacteroides we are not in a position to re-classify strain GNAB 18.

The characterization of the Bacteroides genus by conventional biochemical techniques is time-consuming and some of the tests are unreliable. SDS-PAGE of surface proteins in conjunction with a few selected biochemical tests offers a rapid, reproducible approach to the demonstration of relatedness between an unknown and a type species. It is hoped that the fine degree of accuracy of this analysis will make it possible to distinguish small differences between strains, so that it might even be possible to distinguish between a newly acquired organism and a resident strain in a patient.

This work was supported by the Medical Research Council (grant no. G977/951/S). We are grateful to Professor J. G. Collee for his interest and helpful advice, to Professor B. P. Marmion who initially suggested the approach and to Mr G. Hay and Miss M. D. Byrne for skilled technical assistance. 


\section{REFERENCES}

Collee, J. G., Watt, B., Fowler, E. B. \& Brown, R. (1972). An evaluation of the Gas-Pak system in the culture of anaerobic bacteria. Journal of Applied Bacteriology 35, 71-82.

Duerden, B. I., Holbrook, W. P., Collee, J. G. \& WATT, B. (1976). The characterization of clinically important Gram-negative anaerobic bacilli by conventional bacteriological tests. Journal of Applied Bacteriology 40, 163-188.

FINEGOLD, S. M. (1977). Anaerobic Bacteria in Human Disease. New York: Academic Press.

Holbrook, W. P., Duerden, B. I. \& Deacon, A. G. (1977). The classification of Bacteroides melaninogenicus and related species. Journal of Applied Bacteriology 42, 259-273.

Holdeman, L. V., Cato, E. P. \& Moore, W. E. C. (editors) (1977). Anaerobe Laboratory Manual, 4th edn. Blacksburg, Va, U.S.A.: Anaerobe Laboratory, Virginia Polytechnic Institute and State University.

LAEMMLI, U. K. (1970). Cleavage of structural proteins during the assembly of the head of bacteriophage T4. Nature, London 227, 680-685.

Lowry, O. H., Rosebrough, N. J., FARR, A. L. \& RANDALL, R. J. (1951). Protein measurement with the Folin phenol reagent. Journal of Biological Chemistry 193, 265-275.
Poxton, I. R. \& Sutherland, I. W. (1976). The butanol-soluble proteins of Klebsiella aerogenes. Microbios 15, 93-103.

Strom, A., Dyer, J. K., Marsh, C. \& Tribble, J. L. (1976). Identification and characterization of species of the family Bacteroidaceae by polyacrylamide gel electrophoresis. Journal of Dental Research 35, 252-256.

Swindlehurst, C. A., Shah, H. N., PARr, C. W. \& Williams, R. A. D. (1977). Sodium dodecyl sulphate-polyacrylamide gel electrophoresis of polypeptides from Bacteroides melaninogenicus. Journal of Applied Bacteriology 43, 319-324.

WATT, B. (1973). The influence of carbon dioxide on the growth of obligate and facultative anaerobes on solid media. Journal of Medical Microbiology 6, 307-314.

Willis, A. T. (1977). Anaerobic Bacteriology: Clinical and Laboratory Practice, 3rd edn. London: Butterworths.

Wren, M. W. D., Baldwin, A. W. F., Eldon, C. P. \& SANDERSON, P. J. (1977). The anaerobic culture of clinical specimens: a 14-month study. Journal of Medical Microbiology 10, 49-61. 